\title{
Barriers that impede the effectiveness of precautionary measures of combating the spread of HIV and AIDS: the case of the University of Zululand and Mangosuthu University of Technology
}

\author{
Blessing Mbatha' \\ Department of Communication Science, University of South Africa \\ mbathbt@unisa.ac.za
}

\begin{abstract}
This article explores and identifies the barriers that impede the effectiveness of precautionary measures of fighting the spread of HIV and AIDS in tertiary institutions in KwaZulu Natal, namely, University of Zululand and Mangosuthu University of Technology. This article is informed by the Satisfaction Theory which emphasises the importance of product or service marketing as it determines whether a customer will continue using a product or service or not. The theory indicates that if a customer is satisfied with the service offered by an organisation or a company, then the client may continue using the company's product or service. However, if a client is dissatisfied with the service offered, he or she may decide to discontinue using the particular product or service. The research problem of this study is articulated through the following research questions: why is the pregnancy rate high in tertiary institutions, whereas condoms are freely available? Why is the spread of HIV escalating in tertiary institutions, whereas information on HIV and AIDS is available? And why are precautionary measures to scale down HIV and AIDS less effective? The study targeted only students in two purposively selected tertiary institutions. The quantitative method and stratified random sampling was used. Data was analysed using Statistical Package of Social Sciences (SPSS) and Microsoft excel. The study established that there are many barriers that impede the effectiveness of precautionary measures of fighting the spread of HIV and AIDS in these tertiary institutions. The study further established that precautionary measures of fighting the spread of HIV and AIDS such as condoms are freely available in these tertiary institutions. However, they are not easily accessible as they are only distributed at the clinics. This article recommends that condoms be distributed all over campus, more especially in students' residences because that is where students spend most of their time. In addition, the clinics are not always opened as compared to students' residences.
\end{abstract}

Keywords: HIV; AIDS; University of Zululand; Mangosuthu University of Technology

\section{Introduction}

This article aims to explore and identify the barriers that impede the effectiveness of precautionary measures of preventing the spread of HIV and AIDS in institutions of higher learning in KwaZulu Natal. In essence, the problem investigated in this research pertains to the fact that much has been said about HIV and AIDS and its dangers, however, less has been said about the barriers that impede the effectiveness of precautionary measures of preventing the spread of HIV and AIDS. In addition, this article seeks to provide researchers and health professionals with information that may assist them in their decision making processes and take appropriate actions in the intervention programmes. Furthermore, this article intends to promote, sensitize, and foster research on sexually transmitted diseases (STDs) in tertiary institutions and nationally.

AIDS stands for Acquired Immune Deficiency Syndrome. It is a medical condition. A person is diagnosed with AIDS when his or her immune system is too weak to fight off infections. On the other hand, HIV stands for Human Immunodeficiency Virus. It should be noted that viruses such as HIV cannot grow or reproduce on their own; they need to infect the cells of a living organism in order to replicate (make new copies of themselves). The human immune system usually finds and kills viruses fairly quickly, but HIV attacks the immune system itself, the very thing that would normally get rid of a virus (Avert, 2009). The latter document further reveals that with around 2.7 million people infected with HIV in 2007, there are an estimated 33 million people around the world who are living with HIV, including millions who have developed AIDS. Since AIDS was first discovered in the early 1980s, an unprecedented number of people have been affected by the global AIDS epidemic. AIDS is caused by HIV, a virus that can be passed from person to person through sexual fluids, blood and breast milk. Certain types of behaviour carry a higher risk of HIV transmission. People particularly vulnerable to HIV include injecting drug users, sex workers and men who have sex with men. In many people's minds, HIV and AIDS are closely linked with these groups, which can also lead to greater prejudice against people already treated as outsiders (UNAIDS, 2009 \& Avert,2009).

Despite these factors, it is reported that a vast majority of HIV infections are transmitted through sex between men and women. Nearly half of all adults living with HIV are female. Many Western countries, such as the United Kingdom, have increasing rates of HIV transmission through heterosexual sex. In America, where more than a million people are

I. Blessing Mbatha is a Lecturer in the Department of Communication Science, University of South Africa, South Africa 
living with HIV, heterosexual sex accounts for one third of new diagnoses. As a sexually transmitted infection, HIV particularly affects adolescents and young adults. Deaths of young adults have an especially damaging impact on their families and communities: skills are lost, workforces shrink and children are orphaned. In some African countries, life expectancies have fallen below 40 years, whereas they would have been above 60 without AIDS. There are around I5 million living children who have lost a parent to AIDS (UNAIDS, 2009 \& Avert, 2009).

Djarova (2003) advances the aforementioned views by describing AIDS as a sexually transmitted disease (STD). Thus, its transmission is via body fluids that harbour the Human Immunodeficiency Virus (HIV). It should be noted that HIV and AIDS are diseases that can affect anyone at any time. It is not a disease for gays, African people, or intravenous drug users. Moreover, it is not even exclusively sexually transmitted as it is widely believed, because there are a number of cases of HIV and AIDS due to blood transfusion. Furthermore, Djarova (2009) points out that HIV and AIDS is the most dramatic, pervasive and tragic pandemic (global epidemic) in recent history. Hubley (1995:0I) and Smith (2002) lucidly define AIDS as Acquired Immune Deficiency Syndrome. As the name implies it is a disease caused by a deficiency in the body's immune system. Hubley (1995:02) and Smith (2002) add that it is a syndrome because there are a range of different symptoms which are not always found in each case. Furthermore, they state that it is acquired because AIDS is an infectious disease caused by a virus, which is spread from person to person through a variety of routes. It is evident that barriers that impede the effectiveness of communication messages around HIV and AIDS do exist. However, their nature and scope require a rigorous investigation. Surprisingly, some of the students in tertiary institutions still find it difficult to practice safe sex, notwithstanding the fact that government provides more information and sufficient precautionary measures to combat the spread of HIV and AIDS. This has been confirmed by high pregnancy rates among students. This view is shared by the United States Agency for International Development (2000), which states that despite the efforts made by national governments and non-governmental organisations (NGOs), Southern African populations have been slow to adopt safer sex practices.

\section{Literature review}

This article is informed by the Satisfaction Theory. Satisfaction refers to a customer's "cognitive state of being adequately or inadequately rewarded for the sacrifice they have undergone" (Kim, Yeon \& Park, 2002: I I). It is an important aspect of product or service marketing because it determines whether a customer will continue using a product or service or not. When a customer is satisfied with the service(s) offered by an organisation or a company, the customer is more likely to continue using that company's products or services. However, if a client is dissatisfied with the service offered, the client may decide to discontinue using that particular product or service. Students will therefore prefer not to take precautionary measures if they are not satisfied with them. According to Hayashi, Chen, Ryan and Wu (2004:I), satisfaction was initially defined within the context of job performance as a "pleasure or positive emotional state resulting from the appraisal of one's job". The two authors further define satisfaction from the context of consumption as: "The summary psychological state resulting when the emotion surrounding disconfirmation expectations is coupled with the consumer's prior feelings about the consumption experience". Both definitions highlight a psychological or affective state related to and resulting from a cognitive appraisal of the expectation-performance discrepancy (confirmation) (Hayashi et al, 2004: 2). Kort and Gharbi (2008:3) regard satisfaction as: "An ex post evaluation of consumers' initial (trial) experience with the service, and is captured as a positive feeling (satisfaction), indifference, or negative feeling (dissatisfaction). Therefore the consumer is satisfied when his affect is resulting from his experience fit with his expectation". Satisfaction therefore comes from the use.

\subsection{HIV and AIDS globally}

According to the statistics published at the end of 2007, around 33 million people were living with HIV, the virus that causes AIDS. Each year approximately 2.7 million more people (including adults and children) become infected with HIV and 2 million die of AIDS despite recent improvements in access to antiretroviral treatment (Avert, 2009). The document (Avert, 2009) further reports that although HIV and AIDS are found in all parts of the world, some areas are more afflicted than others. The worst affected region is sub-Saharan Africa, where in a few countries more than one in five adults is infected with HIV. The epidemic is spreading most rapidly in Eastern Europe and Central Asia, where the number of people living with HIV increased to $150 \%$ between $200 \mathrm{I}$ and 2007. The document (Avert, 2009) further indicates more than 25 million people have died of AIDS since 198I and Africa has II.6 million AIDS orphans.

Moreover, UNAIDS (2009) \& Avert (2009) point out that at the end of 2007 , women accounted for $50 \%$ of all adults living with HIV worldwide, with 59\% in sub-Saharan Africa. Noteworthy, young people (under 25 years old) account for half of all new HIV infections worldwide. It is also important to note that in developing and transitional countries, about 9.7 million people are in immediate need of life-saving AIDS drugs and only 2.99 million (31\%) are receiving the drugs. 
According to Avert (2009), the number of people living with HIV has risen from around 8 million in 1990 to 33 million today, and is still growing. Around $67 \%$ of people living with HIV are in sub-Saharan Africa.

\subsection{HIV and AIDS in Africa}

Avert (2009) \& UNAIDS (2009) are of the view that Sub-Saharan Africa is more heavily affected by HIV and AIDS than any other region of the world. An estimated 22 million people are living with HIV in the region which is around two thirds of the global total. In 2007, around I.5 million people died from AIDS in sub-Saharan Africa and 1.9 million people became infected with HIV. Since the beginning of the epidemic, more than eleven million children have been orphaned by AIDS.

The latter documents further point out that in the absence of massively expanded prevention, treatment and care efforts, it is expected that the AIDS death toll in sub-Saharan Africa will continue to rise. This means that the impact of the AIDS epidemic on these societies will be felt most strongly in the course of the next ten years and beyond. Its social and economic consequences are already widely felt, not only in the health sector but also in education, industry, agriculture, transport, human resources and the economy in general. The AIDS epidemic in sub-Saharan Africa threatens to devastate whole communities, rolling back decades of development progress.

\subsection{The impact of HIV and AIDS in South Africa}

Studies conducted by Avert (2009) \& UNAIDS (2009) on the impact of HIV and AIDS in South Africa established that an estimated 5.2 million people were living with HIV and AIDS in South Africa in 2008, more than in any other country. It is believed that in 2008, over 250,000 South Africans died of AIDS. In addition, Avert (2009) notes that national prevalence is around II\%, with some age groups being particularly affected. Almost one-in-three women aged 25-29, and over a quarter of men aged 30-34, are living with HIV. HIV prevalence among those aged two and older also varies by province with the Western Cape (3.8\%) and Northern Cape (5.9\%) being least affected, and Mpumulanga (15.4\%) and KwaZuluNatal (I5.8\%) at the upper end of the scale (Avert, 2009 \& UNAIDS, 2009). The latter document Avert (2009) cautions that HIV in South Africa is transmitted predominantly heterosexually between couples, with mother-to-child transmission being the other main infection route. Moreover, the latter document narrates that the impact of the AIDS epidemic is reflected in the dramatic change in South Africa's mortality rates. The overall number of annual deaths increased sharply from 1997, when 316,559 people died, to 2006 when 607,184 people died. This rise is not necessarily due solely to HIV and AIDS but it is young adults, the age group most affected by AIDS, who are particularly shouldering the burden of the increasing mortality rate. In $2006,41 \%$ of deaths were attributed to $25-49$ year olds, up from $29 \%$ in 1997 . This is a strong indicator that AIDS is a major, if not the principal, factor in the overall rising number of deaths (Avert, 2009 \& UNAIDS, 2009).

\section{Research methodology}

Through a survey, due to the diverse and enormous nature of tertiary institutions in South Africa, the study targeted only students in two purposively selected tertiary institutions in KwaZulu Natal, namely, University of Zululand and Mangosuthu University of Technology. Although it would be interesting to target all tertiary institutions in South Africa, this would require more time, resources and expertise, which can be an object of further study. The following strata were used to choose the population of the study: by gender, $63 \%$ females and $37 \%$ males; by age and by race, $97 \%$ indigenous Africans and 3\% Indians. The study used a stratified random sampling to choose the population of the study. The population being sampled here was as follows: firstly, in 2002, the University of Zululand had a population of five thousand two hundred and twenty two (5222) students (the University of Zululand's Calendar, 2003). On the other hand, also in 2002, the Mangosuthu University of Technology had six thousand three hundred and eighteen students (63l8) (Mangosuthu University of Technikon, 2003). One percent (1\%) from the targeted population was chosen for manageability. The total number of students in both tertiary institutions was eleven thousand five hundred and forty (I I 540). One percent of this total number is one hundred and fourteen (II4). The scientific method applied is as follows: ( $\mathrm{n}$ / $x^{*}$ 100) (number of respondents, divided by whatever number, multiply by one hundred). The same percentage was applied in both tertiary institutions in the following manner; the University of Zululand had 5222 students and $1 \%$ of this is 52 , while Mangosuthu University of Technology was composed of 6318 students of which $1 \%$ is 63 . The overall number of targeted students was II4. A self administered questionnaire that was largely closed - ended or structured $(80 \%)$ was used to collect data. The response rate was $100 \%$ of II 4 distributed questionnaires. Empirical data of the survey was analysed using largely descriptive statistics and with the help of Statistical Package of Social Sciences (SPSS) and Microsoft excel.

\section{Results}

The main aim of the study was to examine the barriers that impede the effectiveness of precautionary measures of preventing the spread of HIV and AIDS in two tertiary institutions in KwaZulu Natal. In order to fulfill the above aim,

Inkanyiso, Jnl Hum \& Soc Sci 2009, I(I) 
many variables were considered in the collection of data. Apart from general background information regarding the respondents, a self administered questionnaire that was largely closed-ended or structured (80\%) helped the researcher to capture data in the following broad areas: awareness of the barriers that impede the effectiveness of precautionary measures of fighting the spread of HIV and AIDS; barriers that impede the effectiveness of precautionary measures of fighting the spread of HIV and AIDS; initial awareness created of HIV and AIDS; sources of information concerning HIV and AIDS; awareness of precautionary measures of HIV and AIDS; abiding by precautionary measures of preventing the spread of HIV; precautionary measures taken by the students not to contract HIV and AIDS; leading ways of contracting HIV; actions taken by tertiary institutions in combating the fuel of HIV and AIDS and strategies that should be applied by the government of South Africa in combating the spread of HIV and AIDS. The response rate was 100\% of (II4) distributed questionnaires.

\subsection{Characteristics of the respondents}

The majority of the respondents $(58 ; 51 \%)$ were from the Mangosuthu University of Technology while $(56 ; 49 \%)$ were from the University of Zululand. The respondents consisted of $63 \%$ females and $37 \%$ males. When it comes to age, majority of the respondents $(72 ; 63 \%)$ were between 15 and 22 years of age. In as far as the race is concerned, the majority of the respondents ( $111 ; 97 \%)$ were indigenous Africans and only $(3 ; 3 \%)$ were Indians.

\subsection{Barriers that impede the effectiveness of precautionary measures of fighting the spread of HIV and AIDS}

The respondents were asked to indicate the barriers that impede the effectiveness of precautionary measures of fighting the spread of HIV and AIDS. The question was open-ended and provided the respondents with flexibility of expressing themselves freely. In addition, respondents were allowed to choose more than one option where necessary and were asked to indicate any other barrier not listed. It should be noted that the table below represents multiple responses.

Table I Barriers that impede the effectiveness of precautionary measures of HIV and AIDS (N=I|4)

\begin{tabular}{|l|c|c|c|}
\hline \multicolumn{1}{|c|}{ Barriers } & MT Institutional affiliation & UZtal \\
\hline Conservative cultures & 7 & 8 & 15 \\
\hline Male migration & 13 & 23 & 36 \\
\hline Poor access to Condoms & 37 & 42 & 79 \\
\hline Re-Marriage & 14 & 10 & 24 \\
\hline Commercial sex workers & 27 & 22 & 49 \\
\hline Poverty & 21 & 18 & 39 \\
\hline Multiple sexual relationships & 27 & 23 & 50 \\
\hline Living single sex quarters & 17 & 16 & 33 \\
\hline Wealth \& higher social status & 22 & 29 & 51 \\
\hline Gender and prevalence of violence & 10 & 8 & 18 \\
\hline
\end{tabular}

The respondents were provided with the list of barriers to choose from as Table I above demonstrates. The majority of the respondents represented by 79 from both tertiary institutions felt that poor access to condoms is a major barrier (61). Male migration was considered to be a barrier and multiple sexual partners got high (50). Avert (2009) points out that it is usually not easy for people to sustain changes in sexual behaviour. In particular, young people often have difficulty remaining abstinent, and women in male-dominated societies are frequently unable to negotiate condom use, let alone abstinence. Many couples are compelled to have unprotected sex in order to have children. Others associate condoms with promiscuity or lack of trust. The document (Avert, 2009) adds that some societies find it difficult to discuss sex openly, and some authorities restrict what subjects can be discussed in the classroom, or in public information campaigns, for moral or religious reasons. In particular, contentious issues include premarital sex, condom use and homosexuality, with the latter being misconstrued to be illegal or seen as a taboo in many parts of the world. Marginalisation of groups at high risk - such as sex workers and men who have sex with men - can be a major hindrance to HIV prevention efforts. Authorities are often unwilling to allocate adequate resources to programmes targeting these groups. Safe male circumcision demands considerable medical resources and some cultures are strongly opposed to the procedure (Avert, 2009). 
4.3 Awareness of precautionary measures of HIV and AIDS

The study sought to establish whether the respondents were aware of precautionary measures that can be taken to prevent contracting HIV and AIDS. In order to measure their responses, a binary choice of $I=Y e s$ and $2=$ No was used. The findings are reflected in table 2 below.

Table 2 Awareness of precautionary measures of HIV and AIDS $(\mathrm{N}=|| 4)$

\begin{tabular}{|c|c|c|c|}
\hline Tertiary institutions & \multicolumn{2}{|c|}{ Awareness } & Total \\
\hline & Yes & No & \\
\hline & $\mathbf{N} \%$ & $\mathbf{N} \%$ & \\
\hline UZ & $56(49 \%)$ & $0(0 \%)$ & $56(49 \%)$ \\
\hline MT & $58(51 \%)$ & $0(0 \%)$ & $58(51 \%)$ \\
\hline Total & II4 (100\%) & $\mathbf{0 ( 0 \% )}$ & $\mathbf{I 1 4 ( 1 0 0 \% )}$ \\
\hline
\end{tabular}

The table above shows that all the respondents (I 14; 100\%) from both tertiary institutions were aware of precautionary measures that can be taken to prevent contracting HIV and AIDS. These findings are not surprising given the fact that the respondents were in tertiary institutions where information on HIV and AIDS is provided in abundance. According to the University of Zululand (2009) the Department of Education has defined the challenge posed by HIV and AIDS to the higher education sub-sector. In response to the challenge, a nationally coordinated programme has been developed with an aim of strengthening the capacity of South African higher education institutions to respond to the causes and consequences of the HIV and AIDS pandemic. Much as the programme is an initiative of the Department of Education, it is effectively owned by the institutions. The University of Zululand recognizes that HIV and AIDS is not merely a health issue but a development issue that concerns the entire community. It is therefore committed to playing an active role in mitigating the impact of the epidemic both on its own constituency of staff and students and on society as a whole. As a result, the University of Zululand has set up an office for the HIV and AIDS programme whose vision is to create a working and learning environment that is supportive, sensitive and responsive to employees and students living with HIV/ AIDS and that encourages employees and students to adopt positive and healthy lifestyles thus taking personal responsibility for preventing the further spread of HIV (University of Zululand, 2009).

4.4 Abiding by precautionary measures of preventing the spread of HIV

The study sought to find out whether the students do abide by precautionary measures for preventing the spread of HIV and AIDS. Respondents were provided with a list options to choose from and were asked to rate them on a Likert scale of I (strongly disagree) through 5 (strongly agree) depending on how it applied to their situations. Table 3 below summarises the responses.

Table 3 Abiding by precautionary measures $(\mathrm{N}=1 \mid 4)$

\begin{tabular}{|l|l|l|l|}
\hline \multicolumn{1}{|c|}{ Variable } & \multicolumn{2}{c|}{ Institutional Affiliation } & \multicolumn{1}{c|}{ Total } \\
\hline & \multicolumn{1}{|c|}{ UZ } & \multicolumn{1}{|c|}{ MT } & \\
\hline Strongly agree & $39(34.2 \%)$ & $42(37 \%)$ & $81(71.2 \%)$ \\
\hline Agree & $14(12.2 \%)$ & $13(11.4 \%)$ & $27(23.6 \%)$ \\
\hline Disagree & $1(0.8 \%)$ & $2(1.7 \%)$ & $3(2.6 \%)$ \\
\hline Strongly disagree & $2(1.7 \%)$ & $\mathrm{I}(0.8 \%)$ & $3(2.6 \%)$ \\
\hline Total & $56(49 \%)$ & $58(51 \%)$ & $114(100 \%)$ \\
\hline
\end{tabular}

Table 3 above shows that a significant number 108 (98\%) of the respondents from both tertiary institutions indicated that they do abide by the precautionary measures of preventing the spread of HIV and AIDS, while only $6(5 \%)$ do not abide by precautionary measures.

4.5. Precautionary measures taken by the students not to contract HIV and AIDS

The study sought to establish precautionary measures students were taking not to spread and contract HIV and AIDS. Respondents were provided with a list of precautionary measures to choose from, depending on how applicable it was to Inkanyiso, Jnl Hum \& Soc Sci 2009, I(I) 
their situations. In addition, the respondents were allowed to choose more than one option where necessary. Table 4 below summarises the responses.

Table 4 Precautionary measures taken by the students $(N=114)$

\begin{tabular}{|lcc|}
\hline Precautionary Measures & Institution \\
\hline & UZ & MT \\
\hline Condoms & 44 & 47 \\
\hline Abstinence & 35 & 22 \\
\hline Faithfulness & 32 & 41 \\
\hline No sex before marriage & 31 & 34 \\
\hline I sexual partner & $\mathbf{3 3}$ & $\mathbf{2 3}$ \\
\hline
\end{tabular}

Table 4 above lucidly indicates that majority of the respondents represented by a significant number (9l; $80 \%)$ from both tertiary institutions use condoms to prevent the spread of HIV and AIDS, while the rest of precautionary measures were used averagely. In support of these findings, Avert (2009) is of the view that condoms are the only form of protection that can both help to stop the transmission of sexually transmitted diseases (STDs) such as HIV and also prevent pregnancy. On the other hand, AIDS.ORG (2009) points out that one can avoid any risk of HIV if he or she practices abstinence.

4.6 Leading ways of contracting HIV

Respondents were asked to indicate the ways which can lead a person to contract HIV. Respondents were provided with a list of different possible ways which can lead a person to contracting HIV and the respondents were allowed to choose more than one as was applicable to their situations. Table 5 below shows the findings emanating from the respondents.

Table 5 Leading ways of contracting $\operatorname{HIV}(\mathrm{N}=1 \mid 4)$

\begin{tabular}{|l|c|}
\hline \multicolumn{1}{|c|}{ Variables } & No of responses \\
\hline Having unprotected sex with an infected person & 114 \\
\hline Contact with infected blood & 114 \\
\hline Using the same razor with an infected person & 114 \\
\hline Sharing of needles with infected person & 104 \\
\hline Kissing infected person & 28 \\
\hline Sharing toothbrushes with infected persons & 09 \\
\hline Bitten by mosquito with HIV & 04 \\
\hline Swimming with infected person & 00 \\
\hline Sharing food with infected & 00 \\
\hline
\end{tabular}

Table 5 above shows that all the respondents (114; 100\%) were of the opinion that having sex with an infected person, contact with infected blood and using same razor with infected person are the leading ways to contracting HIV. Expectedly, none of the respondents said sharing food and swimming are leading ways of contracting HIV. AIDS.ORG (2009) concurs with these findings by pointing out that HIV is not spread easily. One can only get HIV if he or she gets infected blood or sexual fluids into his or her system. The document adds that HIV cannot be transmitted through mosquito bites, coughing or sneezing, sharing household items, or swimming in the same pool with someone infected with HIV. 
4.7 Actions taken by tertiary institutions in combating the spread of HIV and AIDS

Respondents were asked to outline measures taken or provided in their universities in the fight against the spread of HIV and AIDS. Respondents were allowed to mention more than one action as was applicable to their situations. The following responses emanated from the respondents:

Table 6 Measures taken by tertiary institutions $(\mathrm{N}=|| 4)$

\begin{tabular}{|l|c|}
\hline \multicolumn{2}{|c|}{ Responses emanated from the respondents } \\
\hline \multicolumn{1}{|c|}{ Actions } & Number of respondents \\
\hline Condoms are made freely available & 109 \\
\hline Information on HIV \& AIDS is provided & 87 \\
\hline Students are taught about HIV \& AIDS & 41 \\
\hline There is a Research centre for HIV \& AIDS & 25 \\
\hline There are awareness programs for HIV & 19 \\
\hline Students are encouraged to practice safer sex & 13 \\
\hline
\end{tabular}

*The table above represents multiple responses

Table 6 above reveals that the majority of the respondents (109) said that condoms are freely provided, 87 of the respondents from both tertiary institutions indicated that information on HIV and AIDS is provided to them, while only I3 out of II 4 respondents revealed that students are encouraged to practice safe sex. In a nutshell, the results show that tertiary institutions under study are doing well in the fight against the spread of HIV and AIDS. However, the issue of condoms distribution and accessibility remains a course for concern amongst the majority of the students. According to the University of Zululand (website), as a way of mitigating the spread of HIV and AIDS on campus, the University of Zululand was able to establish a voluntary counseling and testing site; establish a student peer education; train members of staff as HIV \& AIDS Counselors; embark on mass communication campaigns and develop material that could be used in the fight against the spread of HIV and AIDS.

4.8 Strategies that should be applied by the government of South Africa in combating the spread of HIV and AIDS Respondents were asked to outline strategies that should be applied by the government of South Africa in combating the spread of HIV and AIDS. The following responses emanated from the respondents:

- Forming groups amongst students who are well trained to deal with HIV and AIDS to teach other students about the dangers of HIV and AIDS;

- Re-instate values and morals;

- More voluntary HIV test centers must be established where people may go for HIV test;

- Students should be taught how to use condoms;

- Both females and males condoms need to be distributed in places where there is a lot of foot traffic;

- New design of condoms should be introduced because students prefer something new, they are now fed-up with the condoms that are provided by the government and thus having a negative attitude towards them. According to the students, government's condoms are weak, therefore, they easily break during sexual activity;

- Students need to be encouraged to abstain, not only to use condoms because condoms are not completely safe;

- Invite severely infected people, those with glaringly obvious symptoms of HIV and AIDS to visit tertiary institutions and teach people about the dangers of HIV and AIDS;

- There should be a compulsory course on HIV and AIDS in all tertiary institutions, especially in first year; and

- Condoms should be distributed to all places where they can be easily accessible to many people at anytime;

\section{Discussions and conclusion}

The aim of this article was to explore and identify the barriers that impede the effectiveness of precautionary measures of fighting the spread of HIV and AIDS in institutions of higher learning in KwaZulu Natal. The study established that one of the major barriers that impede the effectiveness of precautionary measures of combating the spread of HIV and AIDS is poor access to condoms. More especially, at the University of Zululand, condoms are not easily accessible as they are only distributed at the university's clinic. Noteworthy, the majority of respondents (109) indicated that condoms are made freely available in their institutions, however, their (condoms) distribution and accessibility are serious causes for concern. As a result, students suggested that condoms be distributed all over the campus, more especially, in the residences where Inkanyiso, Jnl Hum \& Soc Sci 2009, I(I) 
they spend most of their time. Moreover, students revealed that they are afraid to take condoms in front of other students. Above it all, students indicated that they are also afraid to take condoms in front of the nursing staff as some of these nurses are mother figures to them. The findings further revealed that male migration is also a major barrier in combating the spread of HIV and AIDS.

The review of related literature has indicated that there are precautionary measures of fighting the spread of HIV and AIDS which are essential to protect one from contracting this epidemic. According to the findings, it can be concluded that the respondents are aware of the precautionary measures to be taken in order to combat the spread of HIV and AIDS. This is supported by the majority (79\%) of the respondents who indicated condoms as precautionary measures they use in the fight against spread of HIV and AIDS. Surprisingly, the study established that majority of the students do abide by precautionary measures of preventing the spread of HIV and AIDS. However, this is inconsistent with the statistics of students who are infected with HIV in tertiary institutions (Quality Statistics for VCT, 2008:02). In addition, even the pregnancy rate is high in tertiary institutions and it simply confirms that some of the students are not taking precautionary measures to prevent the unnecessary pregnancy and the spread of sexually transmitted diseases. It should also be pointed out that while the young may be the most vulnerable population, they are also the most receptive to prevention messages and will easily and readily adopt more responsible behaviours" (Centre for African Family Studies, 200I:10).

\section{Recommendations}

There is an urgent need for the provision of information for the purposes of protecting young people against HIV and AIDS. It is worth noting that besides the provision of information to support researchers' and decision makers' activities, there is a need to provide relevant information on HIV transmission to the youths. The study established that barriers that impede the effectiveness of precautionary measures of fighting the spread of HIV and AIDS do exist. However, their nature and scope require a rigorous investigation. Therefore, this article proposes the following recommendations for future research:

- Investigate the feasibility of rolling the study out to a wider cross section of tertiary institutions in order to build a database of HIV and AIDS information to assist with planning and decision making;

- Share best practice/experience between institutions regarding mechanisms/tactics/policies which are most effective in combating and controlling the spread of HIV and AIDS and promoting safe/protected sex; and

- Review current training provision for students in the recognition of precautionary measures of fighting the spread of HIV and AIDS.

\section{References}

AIDS.ORG (2009) Stopping the spread of HIV [Online] http://www.aids.org/factSheets/I50-Stopping-the-Spread-ofHIV.html\#anchor8024 [Accessed 10/09/09]

Avert (2009) HIV and AIDS in Africa [Online] http://www.avert.org/aids-hiv-africa.htm [Accessed 03/I I/09]

Centre for African Family Studies. (200I). Partnering with the private sector to strengthen HIV/AIDS networks. Nairobi: Centre for African Family Studies.

Djarova T.G. (2003). HIV/AIDS. University of Zululand, p.3-40.

Hayashi, A., Chen, C., Ryan, T. and Wu, J. (2004). Role of Social Presence and Moderating Role of Computer Self-Efficacy in Predicting the Continuance Usage of E-Learning Systems. The Journal of Information Systems Education. Summer: I-2. http:// findarticles.com/p/articles/mi_qa404l/is_200407/ai_n9437383/pg_2 Accessed on 2009-03-10

Hubley, J. (1995). The handbook: A guide to the understanding of HIV and AIDS, London: Macmillan.

Kim, M. K., Yeon, G. D. \& Park, M-C. (2002). Determination of Customer Retention for the Korean High-Speed Internet Service. Seoul: Paper delivered at the $14^{\text {th }}$ Biennial International Telecommunications Society Conference, Montreal. June 24-27.

Kort, W. \& Gharbi, J-E. (2008). An experiential epproach of satisfaction in e-learning. Jendouba University. Paper delivered at the $17^{\text {th }}$ Biennial International Telecommunications Society Conference, Montreal. June 24-27.

Leedy, P.D. (1997). Practical research. Planning and designing. $6^{\text {th }}$ ed. Upper Saddle River: Merrill.

Lupton, D., Chapman, S. \& Wong, W.L. (1993). Back to complacency: AIDS in the Australian press, March-September 1990. Health Education Research, 8(1), 5-17

Mangosuthu University of Technology (2009) About Mangosuthu University of Technology [Online] http://www.mut.ac.za/ index.php/admin/About-Mangosuthu-University-of-Technology.html [Accessed 01/09/09]

Quality Statistics for VCT (2008:02). HIV and AIDS statistics at UZ. Unizulu. P2-3

Smith, B. (2002) HIV/AIDS Awareness: Family and Consumer Sciences, Ohio State University

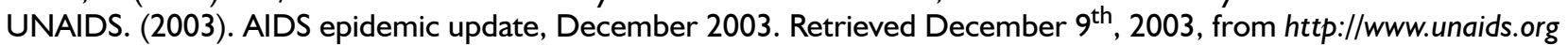

UNAIDS (2009) 2008 Report on the global AIDS epidemic [Online] http://www.unaids.org/en/default.asp [Accessed 02/I I/09]

United States Agency for International Development's. (2000) Corridors of Hope. Available on this website, http//www.fhi.org/ en/hviaids/index.htm [Accessed on 05/06/03]

University of Zululand. (2003). Calender, General. Kwa-Dlangezwa: University of Zululand

University of Zululand (2009) Background-HIV [Online] http://www.uzulu.ac.za/serv_hiv_aids.php [Accessed: 13/I I/09] 